\title{
Cortisol-dependent stress effects on cell distribution in healthy individuals and individuals suffering from chronic adrenal insufficiency
}

\author{
Ashley M. Geiger ${ }^{1}$, M.A., Kenneth P. Pitts ${ }^{1}$, M.A., Joachim Feldkamp², M.D., Clemens \\ Kirschbaum ${ }^{3}$, Ph.D., Jutta M. Wolf ${ }^{1, *}$, Ph.D \\ ${ }^{1}$ Brandeis University, Waltham, MA \\ ${ }^{2}$ Klinikum Bielefeld, Bielefeld, Germany \\ ${ }^{3}$ Technische Universität Dresden, Dresden, Germany
}

Running Head: CORTISOL AND CELL DISTRIBUTION

${ }^{*}$ Corresponding author and person to whom reprint requests should be addressed:

Jutta M. Wolf, Ph.D., Brandeis University, 415 South St., MS 062, Waltham, MA 02453, E-mail:

jmw@brandeis.edu, Phone: 781-736-3297, Fax: 781-736-3291

Conflicts of Interest: The authors declare no conflicts of interest. 


\section{Abstract}

Chronic Adrenal Insufficiency (CAl) is characterized by a lack of glucocorticoid and mineralocorticoid production due to destroyed adrenal cortex cells. However, elevated cortisol secretion is thought to be a central part in a well-orchestrated immune response to stress. This raises the question to what extent lack of cortisol in CAI affects stress-related changes in immune processes.

To address this question, 28 CAl patients (20 females) and 18 healthy individuals ( 11 females) (age: $44.3 \pm 8.4 y r s$.) were exposed to a psychosocial stress test (Trier Social Stress Test: TSST). Half the patients received a $0.03 \mathrm{mg} / \mathrm{kg}$ body weight injection of hydrocortisone (HC) post-TSST to mimic a healthy cortisol stress response. Catecholamines and immune cell composition were assessed in peripheral blood and free cortisol measured in saliva collected before and repeatedly after TSST.

CAI patients showed norepinephrine (NE) stress responses similar to healthy participants, however, epinephrine (E) as well as cortisol levels were significantly lower. HC treatment postTSST resulted in cortisol increases comparable to those observed in healthy participants (interaction effects - NE: $F=1.05, p=.41 ; E: F=2.56, p=.045$; cortisol: $F=13.28, p<.001$ ). Healthy individuals showed the expected pattern of stress-related early lymphocyte increase with subsequent decrease below baseline. The opposite pattern was observed in granulocytes. While exhibiting a similar initial increase, lymphocytes kept increasing over the following two hours in untreated patients. HC treatment buffered this effect (interaction effects - lymphocyte\%: $F=7.31, p<.001$; granulocyte\%: $F=7.71, p<.001)$.

Using CAI in humans as a model confirms cortisol's central involvement in post-stress lymphocyte migration from blood into immune-relevant body compartments. As such, future studies should investigate whether psychosocial stress exposure may put CAI patients at an increased health risk due to attenuated immune responses to pathogens.

Keywords: cell trafficking; chronic adrenal insufficiency; psychosocial stress; cortisol; catecholamines 


\section{Introduction}

Elevated cortisol and catecholamine secretion are thought to be a central part in a wellorchestrated immune response to stress (1). While studied extensively in animals, it is less clear to what extent the inability to mount a cortisol response affects stress-related changes in immune processes in humans. The current study proposes chronic adrenal insufficiency (CAl) as a model for assessing the role of cortisol in stress-related immune cell trafficking.

\subsection{Stress Affects Immune Cell Distribution}

Psychosocial stress is associated with increased activity of the hypothalamus-pituitary-adrenal (HPA) axis as well as the sympathetic nervous system (SNS) (2). The major end products of these systems are the hormones cortisol (HPA axis) and epinephrine and norepinephrine (SNS). Stress-induced release of these mediators has a wide range of effects on somatic systems, which generally are thought of as well-orchestrated and thus primarily protective (3). One immune process of particular interest is the migration of immune cells across vascular endothelium (i.e., cell trafficking), for example, from blood or lymph fluid into tissue or a site of inflammation.

Stress interacts with this process on multiple levels. The fast release of catecholamines occurring within seconds after onset of a stressor increases the number of circulating natural killer (NK)-cells and granulocytes. This process is thought to ensure fast transportation of cells central for innate immunity to sites of tissue damage, thereby reducing the risk for infections (1, $4,5)$. Stress-induced changes in glucocorticoids induce a pronounced decrease in lymphocytes, indicating migration of lymphocytes out of blood and into immune compartments or sites of inflammation (1). Importantly, cell trafficking is a clinically relevant immune function. For example, changes in immune cell composition patterns observed in response the stress of undergoing surgery have been shown to predict speed of recovery post-surgery (6).

\subsection{Methodological Considerations}

To determine whether cortisol is sufficient or necessary for stress-related cell trafficking patterns, lack of hormone and subsequent hormone replacement is the approach of choice (3). Adrenalectomy studies have been helpful in determining the extent to which a lack of cortisol response affects the stress-immune relationship. For example, adrenalectomized animals do not show a stress-induced decline in leukocytes compared to intact animals (7), while administering cortisosterone to these animals restores the response (8). However, adrenalectomy removes the entire adrenal gland, including the medulla. This not only prevents 
the production of glucocorticoids, but also the local production of catecholamines (7), making it difficult to tease apart the effects of a missing cortisol response from altered catecholamine responses. In addition to adrenalectomy studies, glucocorticoid synthesis inhibitors and receptor antagonists have been used to isolate the role of glucocorticoids in stress induced cell trafficking $(9,10)$. However, these approaches acutely remove glucocorticoids from the system and thus do not separate the impact of missing cortisol responsivity from effects of missing basal glucocorticoid levels. Furthermore, they do not allow for investigation of more health-relevant long-term adaptations to a chronic lack of glucocorticoid increases in response to physical and psychosocial stress.

\subsection{The Current Study: Chronic Adrenal Insufficiency}

The current study aimed at finding a model for studying the role of cortisol in stress-related immune cell trafficking that addresses some of the methodological gaps from alternative approaches outlined above. Investigating patients suffering from chronic adrenal insufficiency (CAl) is proposed as a promising approach.

Patients with CAI do not produce any cortisol due to destroyed adrenal cortex cells and thus receive glucocorticoid (and mineralocorticoid) replacement (11-14). This therapy only substitutes basal cortisol levels, while no provisions are made for additional doses during stress. As a result, CAI patients are specifically lacking the ability to mount a cortisol stress response. The first aim of the current study was therefore to confirm the supposed lack of endocrine stress responses in patients with CAl. The second aim was to investigate the effects of missing cortisol stress responses on immune cell trafficking. To distinguish between sufficient and necessary effects of cortisol, half of the CAI patients were treated with $0.03 \mathrm{mg} / \mathrm{kg}$ hydrocortisone i.v. to pharmacologically mimic cortisol stress responses.

\section{Methods}

\subsection{Participants}

A total of 36 patients with CAI and 21 age- and gender-matched healthy participants (HP) were investigated. We excluded five participants for missing one or more blood samples (4 CAI patients), two for missing saliva samples (one CAI patient), three for being under-age (two CAI patients), and one patient for abnormally high norepinephrine levels at baseline (>4SD) and throughout the study protocol (2-3 SD above the mean). Hence, the final sample consisted of 28 
individuals with CAI (20 females) and 18 controls (11 females) with a mean age of 44.33 years (SD = 8.36 years). Based on presence of autoantibodies (adrenocortical autoantibodies, steroid cell antibodies) $(12,15)$ or co-morbidities fulfilling criteria for classification to Autoimmune Polyglandular Syndrome (APS) type 1 or type 2 (16), 19 patients were diagnosed with autoimmune CAI (67.9\%). In four patients, the cause for CAI was former Cushing's disease and five patients did not provide sufficiently detailed information for differential diagnosis.

Half of the CAI patients were randomly assigned to receive $0.03 \mathrm{mg} / \mathrm{kg}$ hydrocortisone (HC) i.v. (Sigma, Berlin) after a psychosocial stress test (CAI-HC: $n=14$ ), while the remaining $n=14$ patients as well as healthy participants (HP) received an injection of $4 \mathrm{ml}$ saline ( $\mathrm{NaCl})$. The CAl$\mathrm{HC}$ and $\mathrm{CAl}-\mathrm{NaCl}$ groups each consisted of 10 females and 4 males and the gender make-up of the three groups did not significantly differ $\left(\mathrm{X}^{2}=.53, p=.77\right)$. The three groups also did not differ in age $\left(F_{2,43}=.36, p=.70 ; \mathrm{CAl}-\mathrm{HC}:\right.$ mean $=43.81, \mathrm{SD}=8.5 ; \mathrm{CAl}-\mathrm{NaCl}$ : mean $=44.87, \mathrm{SD}=$ 7.9; HP-NaCl: mean $=45.06, \mathrm{SD}=9.8)$ or body mass index $\left(\mathrm{BMl}: F_{2,43}=1.31, p=.28 ; \mathrm{CAl}-\mathrm{HC}\right.$ : mean $=23.89, \mathrm{SD}=4.3 ; \mathrm{CAl}-\mathrm{NaCl}:$ mean $=23.98, \mathrm{SD}=2.6 ; \mathrm{HP}-\mathrm{NaCl}:$ mean $=25.40, \mathrm{SD}=$ 4.6). Lastly, the two patient groups did not differ in etiology of $\mathrm{CAl}\left(\mathrm{X}^{2}=4.16, p=.25\right)$ nor the number of years with the disease (CAI-HC: mean $=7.42$ years, $\mathrm{SD}=7.22, \mathrm{CAl}-\mathrm{NaCl}$ : Mean $=$ 10.14 years, $\left.S D=9.90 x^{2}=19.29, p=.31\right)$. The ethics committee of the University of Düsseldorf approved the study protocol.

\subsection{Procedures}

Patients and healthy participants were recruited from across Germany (travel distance: $287 \pm 157 \mathrm{~km} ; t=1.69, p=.20$ ), with patients being referred by the study's endocrinologist (JF). Participants arrived in the laboratory at 1PM and were examined for past or current health problems by the study's physician. CAl participants were asked to postpone their second glucocorticoid replacement dose usually taken around 2PM (mean=13:49h, SD=1h57min) to avoid cortisol levels pre-stressor being significantly higher than in healthy participants. After obtaining written consent, a catheter was inserted into participants' preferred arm. After a 45minute adjustment period allowing stress from catheter insertion to subside, a first blood $(2.7 \mathrm{ml}$ and 9ml EDTA monovettes, Sarstedt, Nümbrecht, Germany) and saliva (Salivette, Sarstedt, Nümbrecht, Germany) sample was collected. Subsequently, participants were exposed to the Trier Social Stress Test (TSST). Shortly after TSST exposure, participants received either a hydrocortisone or placebo injection in a double-blind design. Additional blood and saliva samples were collected 1, 10, 20, 30, 45, 60, 90, and 120 minutes after stress exposure (see Figure 1). 


\subsection{Manipulations}

Pharmacological manipulation: To mimic an acute cortisol stress response, half of the CAI patients received a bolus injection of $0.03 \mathrm{mg} / \mathrm{kg}$ body weight hydrocortisone via catheter. This dose was found to successfully increase cortisol levels by roughly $15 \mathrm{nmol} / \mathrm{l}$ in a pilot study assessing the effects of various doses of hydrocortisone in healthy adults with a wide range in body types. Healthy participants and the remaining patients received a $4 \mathrm{ml}$ saline $(\mathrm{NaCl})$ i.v. bolus injection.

Trier Social Stress Test (TSST): The TSST is a widely used acute laboratory stress test with a strong social-evaluative component. It consists of a three-minute preparation period followed by a five-minute speech tasks and a five-minute mental arithmetic task in front of a two-person panel. It has been shown to reliably elicit both catecholamine and cortisol responses. For more details, see Kirschbaum, Pirke, \& Hellhammer (17).

\subsection{Bioche mical Assays}

Salivary cortisol: Saliva samples were stored at $-30^{\circ} \mathrm{C}$ until analysis. Upon completion of the study, samples were thawed, centrifuged, and free cortisol levels in saliva were measured using a commercially available chemiluminescence assay (IBL, Hamburg, Germany). Samples were measured in duplicates and averaged for subsequent statistical analyses. Inter- and intra-assay CVs were below $8 \%$.

Plasma catecholamines: Immediately after collection, plasma was separated at $4^{\circ} \mathrm{C}, 1600 \times \mathrm{g}$ and stored at $-80^{\circ} \mathrm{C}$. Plasma concentrations of norepinephrine and epinephrine were determined by high-performance liquid chromatography with electrochemical detection (18). Epinephrine levels under detection limit were labeled $5 \mathrm{pg} / \mathrm{ml}$ representing half of the lowest standard.

Immune cell composition: Differential blood counts were performed on blood samples collected pre-TSST as well as 10, 60, and 120 minutes post-TSST. Specifically, after 45 minutes of incubation to allow for EDTA sample equilibration, each sample was measured five times using an AcT Diff Cell counter (Beckman-Coulter, Krefeld, Germany) and average numbers as well as average percentages of monocytes, lymphocytes, and granulocytes were computed for each sample. 


\subsection{Statistical Analyses}

All analyses controlled for age and sex. To assess baseline differences in cortisol, catecholamines, and cell counts and percentages, ANCOVAs were computed. Repeatedmeasures ANCOVAs were used to evaluate changes in the same measures in response to the TSST. Where indicated, Greenhouse-Geisser corrected values are given. Change scores were computed to capture responses to stress as well as post-stress recovery. More specifically, cortisol and norepinephrine increase indices were computed by subtracting the first sample (pre-TSST baseline) from the peak value (individual maximum of the sample taken immediately following the TSST, 10 minutes, or 20 minutes post-TSST). Decrease indices were calculated by subtracting individual minimum value (from sample taken 30, 45, 60, 90, or 120 minutes post-TSST) from the peak value. Cell number and cell percentage response indices were computed by subtracting values at time 1 (pre-stress baseline) from values at time 2 (10 minutes post-stress) for each type of cell (lymphocytes, granulocytes, and monocytes). Recovery following stress was computed by subtracting values at time 2 from values at time 3 (60 minutes post-stress). As for the two-phased endocrine responses, the labels "response" and "recovery" are used to distinguish initial baseline to post-TSST changes from subsequent changes in cell numbers or percentages. Depending on the cell type, both response and recovery can be a positive change (increase) or negative change (decrease). Partial correlations controlling for age and sex were computed between the above indices to test for relationships between endocrine and immune responses.

\section{Results}

\subsection{Baseline Group Comparisons}

Baseline cortisol levels were significantly lower in CAI patients than healthy participants $\left(F_{1,42}=\right.$ $11.00, p=.002)$. While baseline norepinephrine levels were comparable between groups $\left(F_{1,42}=\right.$ 2.06, $p=.16)$, epinephrine levels in CAl patients were either significantly lower than those observed in healthy participants or below detection limit $\left(F_{1,42}=20.02, p<.001\right)$. Lastly, patients and healthy participants did not differ in terms of baseline lymphocyte, granulocyte, or monocyte cell counts or percentages (all $p>.37$ ). 


\subsection{Stress Responses}

\subsubsection{Cortisol and Catecholamine Responses to Stress}

Significant group differences in cortisol responses $(F=13.28, p<.001$; see Table 1 for more details) indicated that untreated CAI participants did not show an increase in cortisol following stress exposure, while cortisol concentrations in healthy participants and CAI patients treated with hydrocortisone peaked 10 to 20 minutes post-TSST and subsequently decreased to baseline levels (see Figure 2, left). Contrarily, epinephrine increased in response to stress in healthy participants only, while both patient groups had very low levels of epinephrine throughout the study ( $F=2.56, p=.045$; see Figure 2, right). No significant differences in norepinephrine stress responses between the three groups were observed $(p=.41)$.

\subsubsection{Cell Trafficking in Response to Stress}

Group comparisons of cell count changes in response to stress are depicted in Figure 3 and statistical values are listed in Table 1. Assessing the numbers of immune cell subtypes present in peripheral blood revealed that all participants showed comparable increases in lymphocyte numbers in response to stress, however, placebo-treated CAl patients exhibited lower numbers of lymphocytes overall $(F=5.17, p=.001)$. While overall granulocyte numbers were higher in $\mathrm{HC}$-treated CAI, only healthy participants showed an increase in granulocyte numbers two hours after stress $(F=3.31, p=.047)$. Monocyte cell counts were not significantly different between groups or over time (all $p>.71$ ).

In terms of immune cell composition in peripheral blood, the three participants groups showed significantly different response patterns in lymphocyte percentages $(F=7.31, p<.001)$. Specifically, all groups showed an initial increase in response to the stressor. After a peak 10 minutes post-stressor, percentage of lymphocytes declined in healthy participants (see Figure 4, left). Contrarily, lymphocyte percentages continued to increase over the following two hours in placebo-treated CAI patients, while the percentage of lymphocytes in HC-treated CAI patients leveled out. Granulocyte percentages showed the opposite patterns, such that subsequent to an initial decrease observed in all participants, percentage of granulocytes increased after stress in healthy participants, leveled off in HC-treated CAI patients, and continued to decrease in placebo-treated CAI patients ( $F=7.71, p<.001$; see Figure 4, right). Monocyte proportion did neither change in response to stress nor did they differ between groups (all $p>.23$ ). 


\subsection{Endocrine-Immune Associations}

Results of partial correlations (controlling for age and sex) between endocrine change indices and cell number and percentage change indices are summarized in Table 2. Lymphocyte\% recovery was negatively correlated with both the magnitude of the cortisol increase following stress $(r=-.40, p=.007)$ and the steepness of the subsequent slope $(r=-.42, p=.004)$, such that a stronger cortisol stress response and slower cortisol clearance were linked to faster migration of lymphocytes back into tissue. Associations between cortisol indices and granulocyte percentage recovery showed the opposite pattern, with granulocyte percentage recovery being positively correlated with both cortisol indices, indicating stronger cortisol stress responses and slower cortisol clearance being linked to a larger proportion of granulocytes being present in peripheral blood 2 hours after stress $(r=.40, p=.007 ; r=.45, p=.002$, respectively). For norepinephrine, neither increase nor recovery was associated with change indices in immune cell subtype compositions (all $p>.40$ ).

Exploratory analyses confirmed that controlling for disease etiology (e.g., autoimmune CAI, Cushing's disease) and disease duration did not change the pattern of findings within patients. The same was true for therapy-related variables, such as daily replacement dosage, medication type (hydrocortisone versus cortisone acetate), or medication regimen (number of doses per day).

\section{Discussion}

The current study utilized CAI as a model for studying the role of cortisol in stress-related immune cell trafficking. As expected, CAl patients demonstrated a lack of cortisol as well as epinephrine increases in response to stress exposure. In terms of immune cell composition changes, untreated CAI patients showed an initial increase in lymphocytes similar to healthy participants, while lymphocytes kept increasing over the following two hours. The opposite pattern was observed in granulocytes. Treatment with $0.03 \mathrm{mg} / \mathrm{kg}$ hydrocortisone resulted in cortisol increases comparable to those observed in healthy participants. Interestingly, hydrocortisone treatment further buffered the CAl-related immune effects. Regardless of treatment, all participants responded to stress exposure with significant increases in norepinephrine, while epinephrine levels were very low in both groups of CAI participants. Lastly, strong associations in the expected directions between cortisol responses and subsequent clearance rates and lymphocyte and granulocyte recoveries were observed. 


\subsection{Stress Responses in Healthy Participants}

Similar to previous reports, the TSST was successful in inducing increases in catecholamines as well as salivary free cortisol in healthy participants in the current study (2). Furthermore, stress-related changes in lymphocyte and granulocyte proportions in peripheral blood are in line with previous findings linking endocrine stress responses to peripheral immune cell subtype composition changes $(1,4,7,8,19)$.

Specifically, acute time-limited increases in catecholamines have been shown to mobilize lymphocytes, specifically natural killer (NK) cells, and granulocytes from depots $(1,4,19)$. The modulation of NK-cell trafficking thereby appears to be beta2-adrenergic receptor (AR)dependent; whereas the transient delayed increase in granulocytes involves alpha-AR stimulation (4). In terms of glucocorticoid effects on immune cell trafficking, previous research has demonstrated that stress-induced changes in glucocorticoids as well as pharmacological glucocorticoid application induce a pronounced decrease in lymphocyte, monocyte, and eosinophil numbers in the blood (20). These effects are interpreted as cells migrating out of circulation into other body compartments as a result of glucocorticoid receptor-mediated (10) alterations in cell adhesion molecules $(21,22)$. Together, stress-induced increases in catecholamines and cortisol may thus help reducing the risk for infections by first mobilizing cells of innate immunity, as indicated by increased numbers of circulating lymphocytes and granulocytes (4), followed by cortisol-mediated migration of cells back into immune compartments or sites of inflammation $(1,7)$.

\subsection{Stress Responses in CAl Patients}

To confirm the involvement of cortisol in the psychosocial stress-induced cell distribution effects, CAI patients were exposed to the same study protocol. As expected, patients with CAl were not able to elicit a cortisol stress response, confirming reports from studies investigating the effects of adrenalectomy on corticosteroid stress response (23). Furthermore, the present findings regarding normal to slightly elevated norepinephrine levels in combination with very low epinephrine levels confirm earlier observations in patients with CAI (24), experimental animals with reduced glucocorticoid synthesis $(25)$, and adrenalectomy $(26,27)$. One study additionally included stress stimulation in patients with isolated glucocorticoid deficiency (28) and found a minimal stress response in epinephrine and slightly increased norepinephrine responses compared to healthy subjects. Based on the data outlined above and on findings of decreased norepinephrine in 21-hydroxylase deficient mice (29), the elevated norepinephrine levels 
observed in CAI have been repeatedly suggested to be an intra-adrenal effect. Specifically, they point towards the role of glucocorticoids in normal functioning of chromaffin cells and their capacity at the transcriptional level to express phenylethanolamine $\mathrm{N}$-methyltransferase (PNMT), the enzyme that converts norepinephrine to epinephrine (30). In other words, lack of cortisol within adrenal tissue results in reduced PNMT levels, and consequently, less conversion from norepinephrine to epinephrine.

These findings show for the first time the dysregulated endocrine response pattern to psychosocial stress expected in patients without endogenous cortisol production. These endocrine response dysregulations were accompanied by distinct stress response patterns in the peripheral composition of immune cell subsets. Specifically, CAl patients showed decreases in lymphocytes accompanied by increases in granulocytes in the first hour following stress, similar to healthy control participants. While the cell subtype composition changed back to prestress ratios in healthy participants over the subsequent hour (i.e., from one to two hours postTSST), lymphocyte percentages continued to decrease and granulocyte percentages continued to increase in CAI patients. These patterns suggest that cortisol is not directly involved in the early processes, but that particularly NK-cell mobilization from depots are mainly catecholamine-mediated $(1,4,19)$. It also implies that norepinephrine is able to make up for the missing epinephrine effects, as NK-cell trafficking is mainly mediated by activation of an adrenergic receptor with high affinity for epinephrine (i.e., beta2-AR). Conversely, cortisol appears to be involved in the later cell distribution effects described above for healthy participants $(10,20)$, such that a lack in cortisol stress responses was accompanied by a lack in redistribution of lymphocytes and granulocytes. CAl patients did not show the late increase in granulocytes observed in healthy participants. This is surprising, given that this effect is thought to be mainly mediated by alpha-AR activation (31), i.e., an adrenergic receptor subtype with high affinity for norepinephrine (32). However, cortisol has been suggested to be involved in this late granulocyte distribution effect as well (20), an observation supported by the present findings.

\subsection{Stress Responses in Hydrocortisone-Treated CAI Patie nts}

To determine to what extent cortisol is not only involved but necessary for the observed stressrelated changes in cell composition, CAl patients were treated with $0.03 \mathrm{mg} / \mathrm{kg}$ hydrocortisone. This treatment was successful in producing cortisol increases comparable to cortisol stress responses seen in healthy participants. Furthermore, while lymphocytes continued to increase over the entire study period in untreated CAI patients, lymphocytes in hydrocortisone-treated 
CAI leveled out after one hour. Thus, although still statistically different from a healthy pattern, hydrocortisone treatment appeared to buffer CAI patients to some extent from a prolonged increase in lymphocytes and as such, partially restored stress effects on cell distribution.

One reason why hydrocortisone treatment did not fully restore the healthy cell trafficking pattern may be the dose of $0.03 \mathrm{mg} / \mathrm{kg}$ being injected as a bolus. Although this treatment resulted in salivary free cortisol levels comparable to those seen in healthy participants immediately after stress, hydrocortisone-treated patients showed faster clearance of cortisol levels thereafter. Thus, cortisol effects may have been terminated earlier in patients than in healthy participants. Shorter cortisol exposure could then, in turn, also explain the lack of late granulocyte increases. Similarly, it has been suggested that cortisol must be present at high doses within the adrenals to restore the PNMT-dependent effect on norepinephrine conversion to epinephrine (30). Consequently, increasing cortisol levels acutely and systemically was insufficient to restore a healthy catecholamine balance. Furthermore, patients in the current study took a total of 24.77 mg hydrocortisone or $41.67 \mathrm{mg}$ cortisone acetate per day in two to three doses. Being exposed to such high concentrations of cortisol several times a day may alter the sensitivity of lymphocytes to glucocorticoid regulation of cell adhesion molecule expression, presenting an alternative explanation for the partial effect of hydrocortisone treatment.

Our findings in hydrocortisone-treated patients as well as the strong associations between cortisol and cell percentage changes confirm a crucial role of cortisol in stress-induced changes in peripheral cell composition. As such, the current findings raise the question whether CAI patients would benefit from additional doses of hydrocortisone during times of stress. However, besides differences in pharmacological dynamics of injected versus orally taken hydrocortisone, increasing evidence points to the fact that patients generally tend to be over-treated (33-35). Chronic over-treatment, in turn, has repeatedly been linked to increased risks of impaired glucose tolerance, obesity, and osteoporosis (36-38). Hence, benefits of adding glucocorticoid doses during times of stress have to be weighted against a patient's individual glucocorticoid replacement regimen in order to avoid increasing the risk for over-treatment related morbidities.

\subsection{Limitations}

The current study has several limitations. First and foremost, the group sizes were relatively small; however, the manipulations appeared to be strong enough to produce all predicted effects, reducing the concerns of potentially missing smaller effects. Furthermore, hydrocortisone and placebo treatment was randomly assigned to patients. Nevertheless, 
hydrocortisone-treated patients showed overall higher peripheral leukocyte numbers, mainly due to elevated granulocytes. This elevated state of immune activation may be linked to the fact that although not statistically different, the hydrocortisone-treated group consisted of almost twice as many patients with an autoimmune disease etiology than the placebo-treated patient group. Although controlling for CAl subtype also did not change the findings presented, future studies may benefit from a more in-depth investigation of CAl etiology on immune cell trafficking.

\subsection{Summary and Outlook}

Chronic adrenal insufficiency provides a human model for investigating the effects of permanently and context-independently altered stress response patterns on bodily systems. Studying such effects in patients with CAI may provide valuable insights into the interplay of endocrine stress systems in the human whole organism and the extent to which it is able to compensate for dysregulations in these systems. This knowledge may help to further our understanding of how altered stress response patterns are associated with physiological diseases and psychological disorders.

In terms of effects of stress systems on immune functions, missing lymphocyte migration out of blood and into other immune compartments, as found in patients with CAI, appeared to be mediated by missing cortisol increases to psychosocial stress. As such, psychosocial stress exposure may put CAI patients as well as other patient groups with reduced glucocorticoid production or sensitivity at an increased health risk due to an attenuated ability of the immune system to mount a timely response to pathogens. 
CORTISOL AND CELL DISTRIBUTION

\section{Acknowledgments}

This work was supported by the German Research Foundation (DFG; KI 537/18; C.K.), by an NIGMS "Brain-Body-Behavior Interface in Learning and Development Across the Lifespan" training grant T32GM084907 (A.M.G.), and by a Department of Defense SMART fellowship (K.P.P.). 


\section{References}

1. Dhabhar FS, Malarkey WB, Neri E, McEwen BS. Stress-induced redistribution of immune cells--from barracks to boulevards to battlefields: a tale of three hormones--Curt Richter Award winner. Psychoneuroendocrinology. 2012 Sep;37(9):1345-68. PubMed PMID: 22727761. Pubmed Central PMCID: 3412918.

2. Dickerson SS, Kemeny ME. Acute stressors and cortisol responses: a theoretical integration and synthesis of laboratory research. Psychol Bull. 2004 May;130(3):355-91. PubMed PMID: 15122924.

3. Sapolsky RM, Romero LM, Munck AU. How do glucocorticoids influence stress responses? Integrating permissive, suppressive, stimulatory, and preparative actions. Endocr Rev. 2000 Feb;21(1):55-89. PubMed PMID: 10696570.

4. Benschop RJ, Rodriguez-Feuerhahn M, Schedlowski M. Catecholamine-induced leukocytosis: early observations, current research, and future directions. Brain Behav Immun. 1996 Jun;10(2):77-91. PubMed PMID: 8811932.

5. Sanders VM. Interdisciplinary research: Noradrenergic regulation of adaptive immunity. Brain Behav Immun. 2006 Jan;20(1):1-8. PubMed PMID: 16140497.

6. Rosenberger PH, Ickovics JR, Epel E, Nadler E, Jokl P, Fulkerson JP, et al. Surgical stress-induced immune cell redistribution profiles predict short-term and long-term postsurgical recovery. A prospective study. J Bone Joint Surg Am. 2009 Dec;91(12):2783-94. PubMed PMID: 19952239. Pubmed Central PMCID: 2780920.

7. Dhabhar FS, McEwen BS. Enhancing versus suppressive effects of stress hormones on skin immune function. Proc Natl Acad Sci U S A. 1999 Feb 2;96(3):1059-64. PubMed PMID: 9927693. Pubmed Central PMCID: 15350.

8. Dhabhar FS, Miller AH, McEwen BS, Spencer RL. Effects of stress on immune cell distribution. Dynamics and hormonal mechanisms. J Immunol. 1995 May 15;154(10):5511-27. PubMed PMID: 7730652.

9. Glover M, Cheng B, Deng X, Pruett S. The role of glucocorticoids in the immediate vs. delayed effects of acute ethanol exposure on cytokine production in a binge drinking model. Int Immunopharmacol. 2011 Jun;11(6):755-61. PubMed PMID: 21315785. Pubmed Central PMCID: 3214649. 
10. Dhabhar FS, Miller AH, McEwen BS, Spencer RL. Stress-induced changes in blood leukocyte distribution. Role of adrenal steroid hormones. J Immunol. 1996 Aug 15;157(4):1638-44. PubMed PMID: 8759750.

11. Ten S, New M, Maclaren N. Clinical review 130: Addison's disease 2001. J Clin Endocrinol Metab. 2001 Jul;86(7):2909-22. PubMed PMID: 11443143.

12. Betterle C, Dal Pra C, Mantero F, Zanchetta R. Autoimmune adrenal insufficiency and autoimmune polyendocrine syndromes: autoantibodies, autoantigens, and their applicability in diagnosis and disease prediction. Endocr Rev. 2002 Jun;23(3):327-64. PubMed PMID: 12050123.

13. Oelkers W. Adrenal insufficiency. NEngl J Med. 1996 Oct 17;335(16):1206-12. PubMed PMID: 8815944.

14. Arlt W, Allolio B. Adrenal insufficiency. Lancet. 2003 May 31;361(9372):1881-93. PubMed PMID: 12788587.

15. Peterson $\mathrm{P}$, Uibo R, Krohn KJ. Adrenal autoimmunity: results and developments. Trends Endocrinol Metab. 2000 Sep;11(7):285-90. PubMed PMID: 10920386.

16. Neufeld M, Maclaren NK, Blizzard RM. Two types of autoimmune Addison's disease associated with different polyglandular autoimmune (PGA) syndromes. Medicine (Baltimore). 1981 Sep;60(5):355-62. PubMed PMID: 7024719.

17. Kirschbaum C, Pirke KM, Hellhammer DH. The 'Trier Social Stress Test'--a tool for investigating psychobiological stress responses in a laboratory setting. Neuropsychobiology. 1993;28(1-2):76-81. PubMed PMID: 8255414.

18. Smedes F, Kraak JC, Poppe H. Simple and fast solvent extraction system for selective and quantitative isolation of adrenaline, noradrenaline and dopamine from plasma and urine. J Chromatogr. 1982 Aug 13;231(1):25-39. PubMed PMID: 7119063.

19. Schedlowski M, Hosch W, Oberbeck R, Benschop RJ, Jacobs R, Raab HR, et al. Catecholamines modulate human NK cell circulation and function via spleenindependent beta 2-adrenergic mechanisms. J Immunol. 1996 Jan 1;156(1):93-9. PubMed PMID: 8598500.

20. Fauci AS, Dale DC. The effect of in vivo hydrocortisone on subpopulations of human lymphocytes. J Clin Invest. 1974 Jan;53(1):240-6. PubMed PMID: 4808638. 
21. Cronstein BN, Kimmel SC, Levin RI, Martiniuk F, Weissmann G. A mechanism for the antiinflammatory effects of corticosteroids: the glucocorticoid receptor regulates leukocyte adhesion to endothelial cells and expression of endothelial-leukocyte adhesion molecule 1 and intercellular adhesion molecule 1. Proc Natl Acad Sci U S A. 1992 Nov 1;89(21):9991-5. PubMed PMID: 1279685.

22. Pitzalis C, Pipitone N, Perretti M. Regulation of leukocyte-endothelial interactions by glucocorticoids. Ann NY Acad Sci. 2002 Jun;966:108-18. PubMed PMID: 12114265.

23. Desser-Wiest L. Corticosterone in serum of adrenalectomized male rats. Osterr Z Onkol. 1976 Sep 13;3(3):70-2. PubMed PMID: 187997.

24. Bornstein SR, Breidert M, Ehrhart-Bornstein M, Kloos B, Scherbaum WA. Plasma catecholamines in patients with Addison's disease. Clin Endocrinol (Oxf). 1995 Feb;42(2):215-8. PubMed PMID: 7704967.

25. Wurtman RJ. Stress and the adrenocortical control of epinephrine synthesis. Metabolism. 2002 Jun;51(6 Suppl 1):11-4. PubMed PMID: 12040535.

26. Eisenhofer G, Friberg P, Pacak K, Goldstein DS, Murphy DL, Tsigos C, et al. Plasma metadrenalines: do they provide useful information about sympatho-adrenal function and catecholamine metabolism? Clin Sci (Lond). 1995 May;88(5):533-42. PubMed PMID: 7614812.

27. Merke DP, Chrousos GP, Eisenhofer G, Weise M, Keil MF, Rogol AD, et al. Adrenomedullary dysplasia and hypofunction in patients with classic 21-hydroxylase deficiency. N Engl J Med. 2000 Nov 9;343(19):1362-8. PubMed PMID: 11070100.

28. Zuckerman-Levin N, Tiosano D, Eisenhofer G, Bornstein S, Hochberg Z. The importance of adrenocortical glucocorticoids for adrenomedullary and physiological response to stress: a study in isolated glucocorticoid deficiency. J Clin Endocrinol Metab. 2001 Dec;86(12):5920-4. PubMed PMID: 11739465.

29. Bornstein SR, Tajima T, Eisenhofer G, Haidan A, Aguilera G. Adrenomedullary function is severely impaired in 21-hydroxylase-deficient mice. Faseb J. 1999 Jul;13(10):1185-94. PubMed PMID: 10385609.

30. Wong DL, Siddall B, Wang W. Hormonal control of rat adrenal phenylethanolamine Nmethyltransferase. Enzyme activity, the final critical pathway. Neuropsychopharmacology. 1995 Nov;13(3):223-34. PubMed PMID: 8602895. 
31. Kavelaars A. Regulated expression of alpha-1 adrenergic receptors in the immune system. Brain Behav Immun. 2002 Dec;16(6):799-807. PubMed PMID: 12480508.

32. Kvetnansky R, Fukuhara K, Pacak K, Cizza G, Goldstein DS, Kopin IJ. Endogenous glucocorticoids restrain catecholamine synthesis and release at rest and during immobilization stress in rats. Endocrinology. 1993 Sep;133(3):1411-9. PubMed PMID: 8396019.

33. Lovas K, Husebye ES. Replacement therapy in Addison's disease. Expert Opin Pharmacother. 2003 Dec;4(12):2145-9. PubMed PMID: 14640913.

34. Peacey SR, Guo CY, Robinson AM, Price A, Giles MA, Eastell R, et al. Glucocorticoid replacement therapy: are patients over treated and does it matter? Clin Endocrinol (Oxf). 1997 Mar;46(3):255-61. PubMed PMID: 9156031.

35. Howlett TA. An assessment of optimal hydrocortisone replacement therapy. Clin Endocrinol (Oxf). 1997 Mar;46(3):263-8. PubMed PMID: 9156032.

36. al-Shoumer KA, Beshyah SA, Niththyananthan R, Johnston DG. Effect of glucocorticoid replacement therapy on glucose tolerance and intermediary metabolites in hypopituitary adults. Clin Endocrinol (Oxf). 1995 Jan;42(1):85-90. PubMed PMID: 7889636.

37. Zelissen PM, Croughs RJ, van Rijk PP, Raymakers JA. Effect of glucocorticoid replacement therapy on bone mineral density in patients with Addison disease. Ann Intern Med. 1994 Feb 1;120(3):207-10. PubMed PMID: 8273983.

38. Florkowski CM, Holmes SJ, Elliot JR, Donald RA, Espiner EA. Bone mineral density is reduced in female but not male subjects with Addison's disease. NZ Med J. 1994 Feb 23;107(972):52-3. PubMed PMID: 8115069. 


\section{Tables}

Table 1. Repeated-measures ANCOVA results assessing changes in cortisol, catecholamines, cell numbers, and cell percentages in response to stress.

\begin{tabular}{|c|c|c|c|c|c|}
\hline & & $\mathrm{df}$ & $\mathrm{F}$ & $p$ & Partial $\eta^{2}$ \\
\hline \multirow[t]{3}{*}{ Cortisol } & Group & 2,41 & 19.57 & $<.001$ & .49 \\
\hline & Time & $3.34,136.74$ & 1.57 & .20 & .04 \\
\hline & Group-by-time & $6.67,136.74$ & 13.28 & $<.001$ & .39 \\
\hline \multirow[t]{3}{*}{ Norepinephrine } & Group & 2,41 & 1.92 & .16 & .09 \\
\hline & Time & $5.12,210.42$ & .29 & .92 & .01 \\
\hline & Group-by-time & $10.26,210.42$ & 1.05 & .41 & .05 \\
\hline \multirow[t]{3}{*}{ Epinephrine } & Group & 2,41 & 13.67 & $<.001$ & .40 \\
\hline & Time & $1.96,80.20$ & .52 & .59 & .01 \\
\hline & Group-by-time & $3.91,80.20$ & 2.56 & .045 & .11 \\
\hline \multirow[t]{3}{*}{ LY\# } & Group & 2,41 & 1.17 & .32 & .05 \\
\hline & Time & $2.08,85.41$ & 49 & .62 & .01 \\
\hline & Group-by-time & $4.17,85.41$ & 5.17 & .001 & .20 \\
\hline \multirow[t]{3}{*}{ GR\# } & Group & 2,41 & 3.09 & .056 & .08 \\
\hline & Time & $1.60,65.59$ & 3.49 & .046 & .13 \\
\hline & Group-by-time & $3.20,65.59$ & 3.31 & .047 & .14 \\
\hline \multirow[t]{3}{*}{ MO\# } & Group & 2,41 & .34 & .72 & .02 \\
\hline & Time & $2.33,95.56$ & .30 & .78 & .01 \\
\hline & Group-by-time & $4.66,95.56$ & .35 & .87 & .02 \\
\hline \multirow[t]{3}{*}{ LY\% } & Group & 2,41 & 1.76 & .19 & .08 \\
\hline & Time & $1.75,71.55$ & .94 & .39 & .02 \\
\hline & Group-by-time & $3.50,71.55$ & 7.31 & $<.001$ & .26 \\
\hline \multirow[t]{3}{*}{ GR\% } & Group & 2,41 & 1.75 & 19 & .08 \\
\hline & Time & $1.73,70.73$ & 1.69 & .20 & .04 \\
\hline & Group-by-time & $3.45,70.73$ & 7.71 & $<.001$ & .27 \\
\hline \multirow[t]{3}{*}{$\mathrm{MO} \%$} & Group & 2,41 & .20 & .82 & .01 \\
\hline & Time & $2.42,99.13$ & 1.45 & .24 & .03 \\
\hline & Group-by-time & $4.84,99.13$ & .30 & .91 & .02 \\
\hline
\end{tabular}

Note. LY = Lymphocytes; GR = Granulocytes; $\mathrm{MO}$ = Monocytes; $\#$ = number; $\%$ = percentage 


\section{CORTISOL AND CELL DISTRIBUTION}

Table 2. Partial correlations between response and recovery indices for cortisol, norepinephrine, cell numbers and cell percentages.

\begin{tabular}{llllllllllllll}
\hline & & Diff & 1. & 2. & 3. & 4. & 5. & 6. & 7. & 8. & 9. & 10. \\
\hline 1. & Cortisol increase & 1 & - & $.93^{\star \star}$ & .09 & .08 & .09 & $-.40^{\star}$ & -.12 & $.40^{\star}$ & .05 & -.12 \\
\hline 2. & Cortisol decrease & 1 & $.93^{\star \star}$ & - & .02 & -.01 & .14 & $-.42^{\star}$ & -.11 & $.45^{\star}$ & -.08 & -.18 \\
\hline 3. & NE increase & 3 & .09 & .02 & - & $.66^{\star \star}$ & .13 & -.01 & -.12 & -.01 & -.04 & .09 \\
\hline 4. & NE decrease & 3 & .08 & -.01 & $.66^{\star \star}$ & - & .10 & .11 & -.09 & -.11 & -.03 & .02 \\
\hline 5. & LY\% response & 3 & .09 & .14 & .13 & .10 & - & .14 & $-.91^{\star \star}$ & -.21 & $-.28^{\wedge}$ & .19 \\
\hline 6. & LY\% recovery & 2 & $-.40^{\star}$ & $-.42^{\star}$ & -.01 & .11 & .14 & - & -.15 & $-.94^{\star \star}$ & -.002 & .03 \\
\hline 7. & GR\% response & 3 & -.12 & -.11 & -.12 & -.09 & $-.91^{\star \star}$ & -.15 & - & .17 & -.15 & -.08 \\
\hline 8. & GR\% recovery & 2 & $.40^{\star}$ & $.45^{\star}$ & -.01 & -.11 & -.21 & $-.94^{\star \star}$ & .17 & - & .09 & $-.35^{\star}$ \\
\hline 9. & MO\% response & 3 & .05 & -.08 & -.04 & -.03 & $-.28^{\wedge}$ & -.002 & -.15 & .09 & - & $-.27^{\wedge}$ \\
\hline 10. & MO\% recovery & 3 & -.12 & -.18 & .09 & .02 & .19 & .03 & -.08 & $-.35^{\star}$ & $-.27^{\wedge}$ & -
\end{tabular}

Note. ${ }^{*} \mathrm{p}<.001,{ }^{*} \mathrm{p}<.05,{ }^{\wedge} \mathrm{p}<.10 ; \mathrm{NE}=$ Norepinephrine;

DIFF: MANOVA post-hoc Tukey test: 1 : $(\mathrm{HP}-\mathrm{NaCl}=\mathrm{CAl}-\mathrm{HC}) \neq \mathrm{CAl}-\mathrm{NaCl} ; 2: \mathrm{HP}-\mathrm{NaCl} \neq(\mathrm{CAl}-\mathrm{HC}=\mathrm{CAl}-\mathrm{NaCl}) ; 3: \mathrm{HP}-\mathrm{NaCl}=\mathrm{CAl}-$ $\mathrm{HC}=\mathrm{CAl}-\mathrm{NaCl}$ 


\section{Figures}

\section{Figure 1.}

Study protocol diagram indicating blood and saliva collection times relative to TSST exposure.

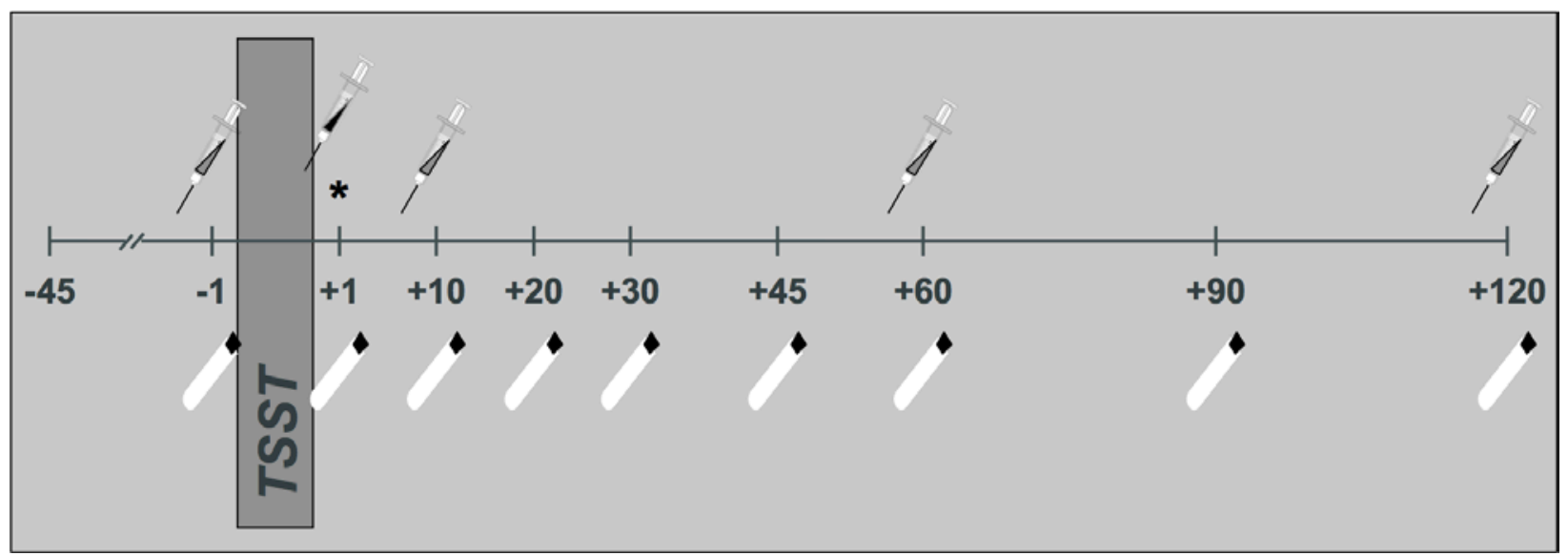

${ }^{*} \mathrm{HC}$ or $\mathrm{NaCl}$ injection 
CORTISOL AND CELL DISTRIBUTION

\section{Figure 2.}

Comparisons of cortisol and catecholamine stress responses across the three study groups.
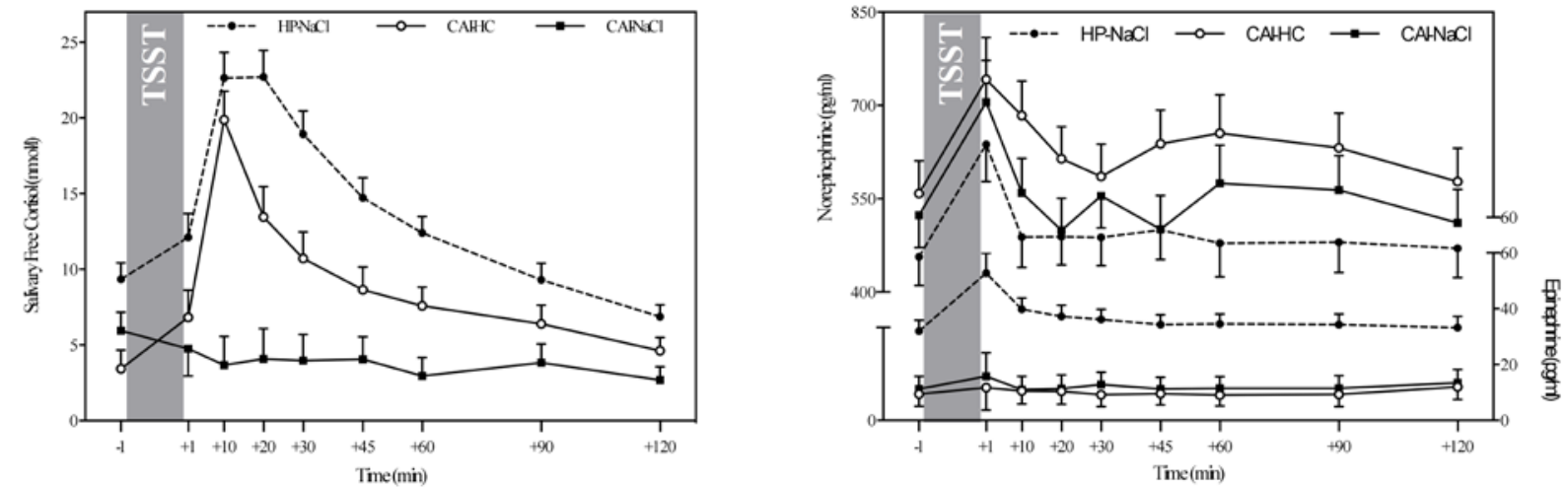

Note. $\mathrm{HP}-\mathrm{NaCl}=$ placebo-treated healthy participants, $\mathrm{CAl}-\mathrm{HC}=\mathrm{CAI}$ patients treated with hydrocortisone; $\mathrm{CAl}-\mathrm{NaCl}$ = placebo-treated CAl patients 


\section{Figure 3.}

Changes in cell counts in response to stress for each of the study groups.
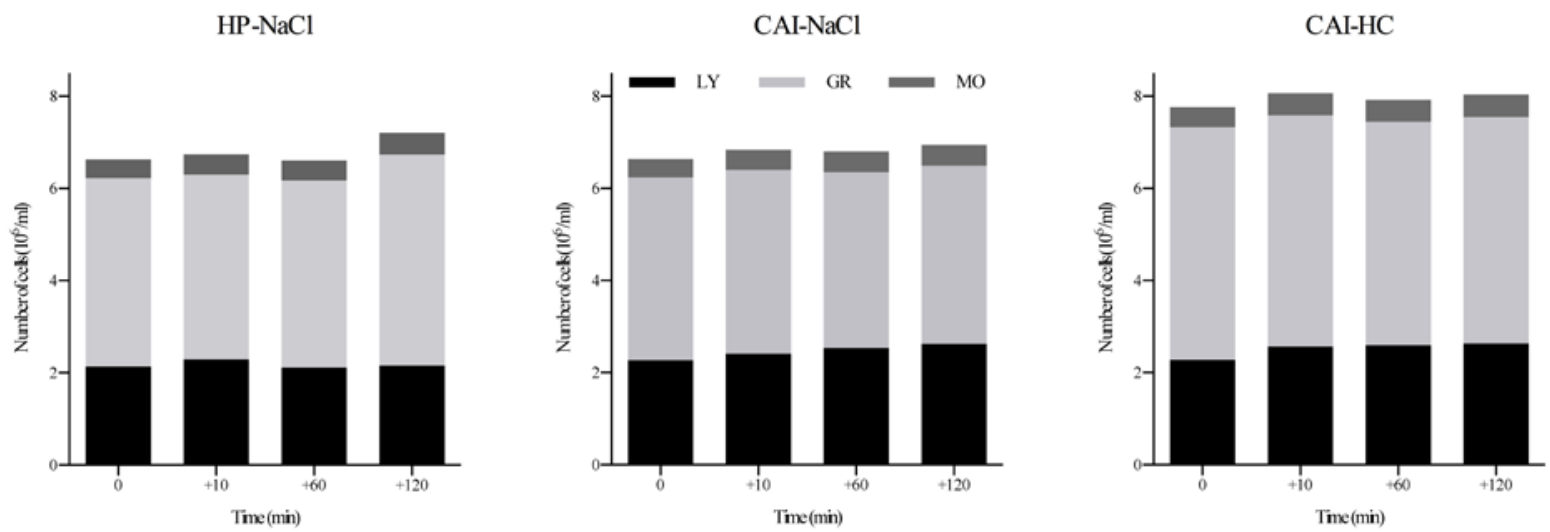

Note. $\mathrm{HP}-\mathrm{NaCl}=$ placebo-treated healthy participants, $\mathrm{CAI}-\mathrm{HC}=\mathrm{CAI}$ patients treated with hydrocortisone; $\mathrm{CAl}-\mathrm{NaCl}$ = placebo-treated CAl patients 
CORTISOL AND CELL DISTRIBUTION

Figure 4.

Group comparisons of stress-related changes in lymphocyte percentages (left) and granulocyte percentages (right).
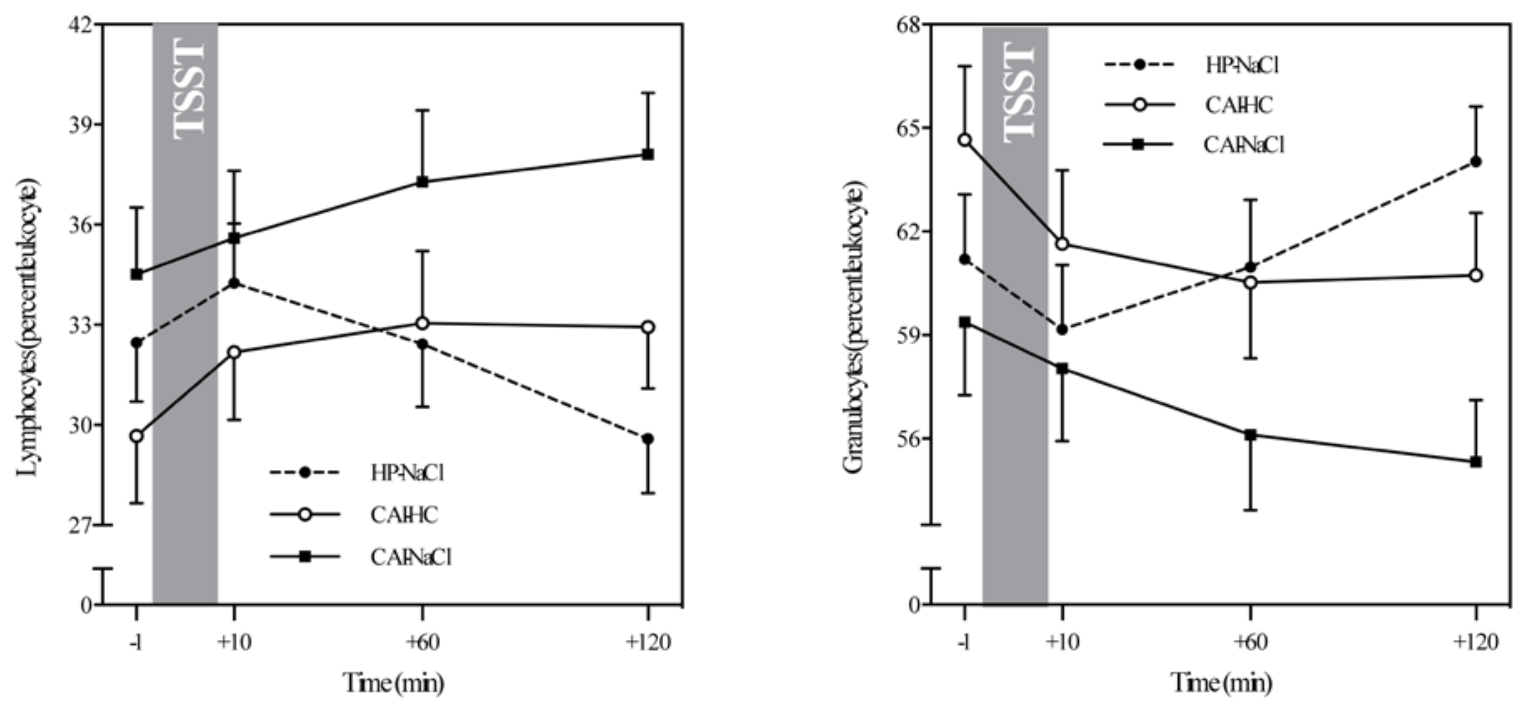

Note. $\mathrm{HP}-\mathrm{NaCl}=$ placebo-treated healthy participants, $\mathrm{CAl}-\mathrm{HC}=\mathrm{CAl}$ patients treated with hydrocortisone; $\mathrm{CAl}-\mathrm{NaCl}$ = placebo-treated CAI patients 